\title{
La competencia literaria: aprender a jugar/desmontar [(dé) jouer] la maestría
}

Por Yves Citton

\section{Resumen}

Ante la problemática: ¿Qué aprendemos al estudiar la literatura?; este artículo responde: Aprendemos a jugar con la maestría y a desmontarla [la déjouer]. Comenzaremos por definir la actividad interpretativa con la ayuda del concepto de "transducción", tal como lo entiende de Gilbert Simondon, para luego explorar algunos alcances de este concepto. Luego se esbozarán ocho proposiciones ejemplificadas con diversos pasajes tomados de Diderot, Potocki, Barthes, Deleuze y Rancière, a fin de comprender cómo la maestría literaria puede ser jugada [jouée] para desmontar [déjouer] la maestría con que se disfrazan los saberes dominantes.

Palabras clave: Literatura, competencia, saberes, maestría, espectáculo, transducción, ambivalencia, emancipación

\section{Nota de los traductores \\ Bryan David Green y Cecilia Katunaric}

La traducción de este ensayo tiene un doble propósito. Por un lado, trata un tema muy atingente al desarrollo de los estudios literarios en el contexto nacional: la manía de imponer a la formación universitaria un paradigma de "competencias" que confunde el aprendizaje con la aplicación de rúbricas y encuestas. Por otro lado, el texto representa una acotada muestra del pensamiento de un crítico literario todavía poco conocido en lengua castellana, a pesar de su productividad y visibilidad en el mundo francófono y angloparlante. Este ensayo sintetiza la defensa (ontológica, epistemológica y ética) de los estudios literarios que Citton ha desplegado magistralmente en Lire, interpréter, actualiser (publicado por primera vez en 2007; reeditada y aumentada en 2016). Aquí se aprecia la mezcla del rigor intelectual, la erudición y el espíritu lúdico que caracteriza a su obra crítica. Si, por un lado, Citton es especialista en la literatura francesa clásica del siglo de las Luces (el spinozismo, Diderot, Potocki), su trabajo académico ha demostrado cómo las obras canónicas que inauguran la "modernidad" en Francia pueden ser actualizadas para responder a las disyuntivas éticas y políticas que definen nuestra situación contemporánea a nivel mundial.

El carácter lúdico de este ensayo presenta un desafío para los traductores, ya que las alusiones, las resonancias, y los juegos de palabras - los cuales dan particular 
espesor al texto- a veces resultan difíciles de traducir al castellano. Por ejemplo, el mismo título presenta una polisemia compleja, cuyo sentido se despliega a lo largo del texto. A diferencia de las distintas equivalentes en español elegidas para captar su sentido en cada caso particular, las palabras "jouer" (jugar, interpretar un papel, apostar), "déjouer" (desmontar, fustrar, fracasar) y "enjeux" (apuesta, envite, alcances) generan enlaces entre distintos saberes y campos: la academia, el juego, el mercado y el espectáculo. Es la yuxtaposición de estos campos que genera el proceso de transducción que propone Citton como modelo del "juego literario". En su defensa de los estudios literarios como un tipo de maestría ("maîtrise" como un saber u oficio que requiere de un arduo y prolongado proceso de aprendizaje y aplicación práctica) dedicada a desenmascarar los discursos dominantes que reducen el mundo a dicotomías fáciles ("maîtrise" como el dominio de un grupo minoritario que consolida su poder a través del embrutecimiento de la mayoría) Citton entreteje lo lúdico (tanto en el sentido del juego desinteresado como en el sentido de una apuesta sobre algún resultado indeterminado) y lo performativo (el mundo del escenario y del espectáculo). Es decir, para Citton, emprender una interpretación literaria es montar una performance que apuesta por desmontar los montajes que regulan y limitan nuestras posibilidades de actuar en el mundo. Esto dicho, nosotros hemos emprendido esta aventura intelectual como un ejercicio de traducción (y transducción) al modo de los experimentos pedagógicos de Joseph Jacotot, aludidos en el texto de Citton; más que a la fidelidad a la fuente, apostamos por el valor que otros podrán sacar de él al actualizarlo desde sus circunstancias particulares. 


\section{La experimentación literaria como juego de transducción incontrolable}

¿En qué clase de "maestro" te conviertes al obtener una maestría en Letras [Master de Lettres]? ¿En qué consiste aquel "juego con la letra” que le da su especificidad a la competencia literaria?" Hablar de un "saber interpretativo", como lo hacían los semiólogos de la escuela greimasiana durante los años 70, me parecería engañoso. Ciertamente, el dominio de los procedimientos implicados en la construcción del sentido supone una fuerte dimensión técnica, por lo que merece entrar en la categoría de los saberes (en los confines de la lexicología, la etimología, de la gramática, la retórica, la pragmática y la semiótica). Si el literato puede distinguirse del lingüista, es porque establece con el texto que estudia no tanto una relación de saber sino una de experimentación. Aunque la experimentación no es nada incompatible con el saber, puesto que constituye un momento de la investigación "científica", la experimentación interpretativa que ejerce el literato participa en un juego de transducción incontrolable que revienta el marco tranquilizador dentro del cual evolucionan los saberes de carácter científico o técnico.

Yo retomo el término de transducción del filósofo Gilbert Simondon, quien entiende por ese concepto "una operación física, biológica, mental, social, por la cual una actividad se propaga paso a paso al interior de un dominio" (25) o a través de dominios aparentemente separados. ${ }^{2}$ La interpretación surgiría de un juego de transducción en la medida de que traslada un texto o una frase de una época a otra, de un dominio de saber a otro, de una referencia a otra, a través de

1 [Nota del autor] En cuanto a la naturaleza lúdica de la lectura literaria, desde luego remito al lector al libro de Michel Picard, La lecture comme jeu. Essai sur la littérature. Michel Picard (1986). Minuit.

2 [Nota de los traductores] Dada la importancia del concepto para la tesis de Citton, merece la pena citar el pasaje referido in extenso: "Entendemos por transducción una operación física, biológica, mental, social, por la cual una actividad se propaga paso a paso al interior de un dominio, generando esta propagación a partir de una estructuración del dominio realizada entre un lugar y otro: cada región de la estructura así constituida sirve a la siguiente región de principio y modelo, de semilla de su constitución. Un cristal que, a partir de un germen muy pequeño, se ensancha y se extiende por todos lados dentro de su aguamadre sobresaturada nos brinda la imagen más simple de la operación transductiva: cada capa molecular ya constituida sirve de base estructurante para la capa en proceso de formación; el resultado es una estructura reticular amplificante. La operación transductiva es una individuación que avanza; en el dominio físico, esta puede efectuarse del modo más simple a través de la repetición progresiva; pero en los dominios más complejos, como los de la metaestabilidad vital o la problemática psíquica, puede avanzar con un paso constantemente variable y extenderse en un dominio de heterogeneidad; hay transducción cuando existe una actividad que parte desde el centro del ser estructural y funcional, y se extiende en diversas direcciones, como si que aparecieran múltiples dimensiones del ser en torno a ese centro; la transducción es la aparición correlativa de dimensiones y estructuras en torno a un ser preindividual tensionado, es decir, un ser que es más que una unidad y más que una identidad, y que todavía no se fractura en múltiples dimensiones desfasadas consigo mismo". 
las diferencias, las disparidades e incluso la incompatibilidad que los separa. Este juego consiste en seleccionar un elemento textual, sacarlo de su contexto original, desplazarlo para que entre en resonancia con un nuevo contexto, y dejar que se propoguen gradualmente las resonancias nuevas que induce dentro de ese nuevo contexto. ${ }^{3}$ Leer Diderot de forma literaria significa conducir su habla a través de todo lo que nos separa de él, para así permitir que ese habla nos diga algo hoy y que siga produciendo resonancias sugerentes desde el interior de nuestras inquietudes actuales.

Situar el proceso de transducción en el centro del trabajo de la interpretación implica, entonces, - entre otras cosas - que este trabajo no aspire a una verdad-adequatio, evaluada según su conformidad con un real pre-existente. Limitarse a juzgar el valor de una interpretación de Diderot, a la luz de lo que significaban sus escritos en la época de su composición, me parece traicionar profundamente la dinámica propia de la aventura literaria. Esta lectura aspira en última instancia a otro tipo de verdad, una verdad-aletheia, cuyo valor es determinado por las nuevas relaciones que permite generar. Lejos de basarse en la conformidad entre lo que el intérprete hace decir a las palabras del texto y lo que el autor pudo tener en mente al escribirlo, las ganancias del juego literario se basan en la disparidad que separa el contexto de llegada y el contexto de partida. Estas ganancias no se miden, al final del juego, en términos de reencuentros, sino de descubrimientos: su mérito no reside tanto en lo que reconstituyen (del pasado) como en las nuevas relaciones que permiten instituir (en el porvenir). ${ }^{4}$

La experimentación literaria es un juego de transducción incontrolable porque jamás puede anticipar cuáles relaciones serán instituidas mañana a partir de las resonancias que pone en marcha hoy. No podemos echar mano a la letra [faire jouer la lettre] de un texto sin exponernos al riesgo de que la letra nos juegue una mala pasada [la lettre se joue de nous], subvirtiendo nuestras mejores intenciones, nuestro saber más sólido, o nuestra maestría más afianzada de la lengua. Jugar el juego de la transducción (literaria u otra) es aceptar ser el portador (miope, tentativo y sonámbulo) de un proceso transindividual de propagación y transformación que nos arrastra según su propia dinámica, más que por nuestros objetivos intencionales.

Tanto para el autor del texto literario como para su intérprete, este juego combina el esfuerzo por el máximo control sobre su propio rendimiento [performance] y la apuesta arriesgada sobre el resultado final de un juego colectivo que necesa-

3 [Nota del autor] Sobre este punto ver Introduction à l'étude des textes. Michel Charles (1998). Seuil.

4 [Nota de autor]. Para un intento de justificar estas afirmaciones excesivamente simplificadas, remito al lector a mi libro, Lier, interpréter, actualiser. Pourquoi les études littéraires? (2007). Éditions Amsterdam. 
riamente se escapa a cualquier control [maîtrise] individual. Como es el caso de todo jugador, la incertidumbre inherente a las dimensiones inmanejables del juego, junto con las expectativas y los temores que suscitan, constituyen una motivación esencial para quien decide entrar en el juego.

\section{Jugar a la maestría para desmontar la maestría}

En la medida en que moviliza los conocimientos técnicos con el fin de emplearlos en juegos de transducción con resultados imprevisibles, la experimentación literaria aspira a cierta maestría solo para superar los límites de la maestría en sí misma. Desde luego, se trata de convertirse en maestro y revindicar una competencia claramente identificable, que exige un aprendizaje paciente, metódico y riguroso, cuya realización institucional es ardua y sacrificada. No obstante, también se trata de orientar este aprendizaje hacia la posibilidad de abandonar en última instancia - la posición del maestro, puesto que su realización [performance] tendrá por objetivo catalizar una transducción cuyo resultado se le escapa a quien lo gatilló.

Se puede decir que el literato "pone en juego su competencia” [“joue sa compétence"] con cada experimento textual, de la misma manera que el jugador prueba su suerte (o arriesga perder hasta la camisa) en cada partida de póker. La competencia es lo que aceptamos poner en juego [(re)mettre en jeu] (y en entredicho) frente a cada texto en particular. Por consiguiente, podemos sospechar que el literato algunos críticos de la deconstrucción y algunos jurados de oposiciones no dudan en hacerlo_ “juega a la competencia" en el sentido peyorativo del bluff o de la impostura. Esta suspicacia es parte integral del juego literario, y debe ser asumida como tal. Solo sabremos lo que vale "realmente" mi novela o mi construcción interpretativa en "el final del juego", cuando se desvanezcan las ilusiones y las miopías del presente. Dado que los dividendos se miden por las relaciones cuya emergencia se catalizará a futuro, la falta actual de un garante (que se precipite a reclamar en contra del bluff o la impostura) siempre podrá ser compensado por los efectos de resonancia esperados en el futuro.

Como bien saben los jugadores de póker, a menudo es a través de la estrecha y peligrosa puerta del bluff que se esgrime una estrategia que ganará la apuesta, ya que los efectos de la creencia pueden ser tan decisivos como las posesiones materiales. Puedo convertirme efectivamente en un maestro del juego (become a master) ${ }^{5}$ si me limito a veces a hacer el papel [jouer el rôle] de quien tendría lo suficiente para conti-

5 [Nota de los traductores] Inglés en el original. Alusión al título del congreso (Unbecoming Masters, New York University, 2009) donde se leyó la primera versión de este ensayo. 
nuar con la partida (aún cuando no tenga nada en la mano), todo el arte del juego consiste precisamente en saber en qué momento y según qué procedimientos se debe a veces jugar, y otras veces desmontar [déjouer] la maestría.

Esta disyuntiva ante el valor "real" de las prácticas literarias se debe a su proyección hacia el futuro. Desde este punto de vista, proponer una interpretación se asemejaría a lanzar una acción en la bolsa o a iniciar un proyecto político en la esfera mediática: equivale a arrojar una propuesta cuyo valor solo se cobrará en la medida de que capte los deseos y las creencias del público que busca convencer. Todos entendemos implícitamente que los deseos y las creencias constituyen un elemento esencial de la producción (humana) de la realidad y que la maestría fingida puede producir una maestría efectiva, pero aún no hemos comenzado a sacar las consecuencias epistemológicas y ontológicas de esta intuición. Es sobre todo por su capacidad de abrir posibilidades que la actividad literaria (creativa e interpretativa) contribuye a la constitución de nuestra realidad social, y lo posible se escapa, por su propia naturaleza, de cualquier esfuerzo de circunscripción dentro de los límites de lo dado y empíricamente observable.

Ante los ataques ideológicos y presupuestarios a los que se exponen los estudios literarios, así como la indiferencia que los amenaza tal vez más que cualquier tipo de ataque explícito esgrimido en su contra, me parece necesario reafirmar cuatro tesis generales sobre la naturaleza de la competencia que se ejerce en la investigación literaria:

a) Los estudios literarios se basan en la adquisición y el dominio activo de un saber técnico riguroso, cuyo fomento requiere de instituciones exigentes y costosas, productoras de una competencia muy particular.

b) Mientras que el saber y la maestría implicados en este aprendizaje pueden a veces someterse a verificaciones cuantitativas y objetivas, la competencia literaria en sí no puede ponerse a prueba de forma empírica: esta surge de un tipo de investigación cuyos resultados son prácticamente indecidibles (puesto que siempre serán descontados del porvenir).

c) Por lo tanto, debemos aceptar el hecho de que la competencia literaria interpretada (como bluff) a menudo no puede ser distinguida de una competencia "real", y que el maestro en literatura se confunde a veces con aquel que no hace sino interpretar el papel de maestro [jouer la maîtrise]. 
d) Gracias a esta incertidumbre — inherente a su condición de realidad—, la competencia literaria se encuentra en una posición privilegiada para poner en tela de juicio cualquier pretensión de competencia. Al mismo tiempo que se sospecha que el literato solo juega a la maestría, este también dispone de una competencia muy particular, y eminentemente valiosa: la de desmontar la maestría.

\section{Maestría y "modernidad"}

Para ilustrar de forma menos abstracta lo que he planteado hasta ahora con una aproximación excesivamente teórica, me apoyaré en un reducido corpus de cuatro autores (Denis Diderot, Jean Potocki, Roland Barthes y Jacques Rancière), de los cuales extraeré ocho proposiciones que me permitirán precisar más concretamente cómo la maestría literaria puede ser jugada a fin de desmontar la maestría. En cada caso, esbozaré una proposición asertiva, para la cual yo solo avanzaré algunas líneas de argumentación posibles que cada uno pueda desarrollar con mayor profundidad por su cuenta, siguiendo sus propios intereses y conocimientos, según las modalidades imprevisibles e interminables de los procesos de transducción.

Desde su emergencia, la modernidad ha contrapuesto sus pretensiones filosóficas de maestría con las prácticas literarias que procuran desmontar las trampas e imposturas de esta maestría.

En un artículo dedicado a denunciar los peligros de la actitud "postmoderna", Cornelius Castoriadis (1990) caracteriza la "modernidad" como suspendida (de forma conflictiva) entre un proyecto de maestría racional y un proyecto de autonomía. A partir de Rabelais y Cyrano de Bergerac, podemos rastrear la forma en que los relatos literarios han ofrecido un campo de expresión y ejercicio privilegiado a dicha tensión conflictiva; la autonomía propia de la expresión literaria (paratopía enunciativa, imaginación ficcional, juego con las virtualidades de la lengua) contribuye simultáneamente a socavar y reconstituir sobre nuevas bases "la expansión ilimitada de la maestría racional". La obra policéfala de Diderot (indisociablemente enciclopédica y ficcional) constituye un ejemplo perfecto de esta tensión y de su productividad, en la medida en que el sistema filosófico más aparentemente restringido (el racionalismo necesarista de Spinoza) se ve todo el tiempo agujereado, dinamizado y revitalizado por una libertad de escritura que solo responde a sus propias leyes poéticas. Jacques le fataliste es así la novela más representativa de la "modernidad", como la define Castoriadis, puesto que juega a la maestría racional que constituye el horizonte de todo el proyecto intelectual spinozista dentro del 
espacio de un dispositivo literario lúdico y dramático a la vez, que denuncia sus peligros al mismo tiempo que actualiza su potencial emancipador. ${ }^{6}$

La postura literaria, en la época moderna, insiste en meterse en el lugar del siervo que desmonta las vanas pretensiones de los maestros del momento.

Jacques le fataliste también sirve de emblema ya que escenifica la inteligencia superior de un sirviente que se las ingenia para exponer la incompetencia cómica de su amo (a most unbecoming master). ${ }^{7}$ De este modo, se puede atisbar una postura literaria hecha de una aparente humildad (nos ponemos del lado de los sirvientes, los excluidos, los marginados, las mujeres, los indecisos, los impotentes, los desposeídos, y de aquellos que hablan o escriben porque no pueden "hacer"), pero que desemboca repentinamente en el cuestionamiento despiadado de las pretensiones de la maestría y los valores dominantes de la época. Esta es la postura que me parece que encarna el estilo de intervención practicado por Roland Barthes en sus cursos de semiótica literaria impartidos en el Collège de France entre 1976 y 1980. Superando las pretensiones científicas de la semiótica estructuralista, Barthes revindica una aproximación literaria para desmontar los paradigmas de las "ciencias humanas" y de las opiniones dominantes. Consagrado como "maître a penser" ("maestro pensador") por el Collège de France, él se limita a pronunciar una discurso doméstico que habla de su hogar y de sus fantasías privadas en vez de exhibir la maestría de un Saber universalista. Aprovechándose del hecho de que la literatura ha sido despojada de su antigua majestuosidad y se ha convertido en una reliquia en vía de extinción bajo la presión mediática de las imágenes y soundbites, Barthes transmuta este debilitamiento cultural en una fuente de nueva fortaleza, porque devuelve a la reflexión literaria toda la potencia creativa propia de las prácticas minoritarias (en el sentido que Deleuze otorga al término). Bajo la hegemonía de los economistas, los administradores y los presentadores estrellas de televisión, apropiarse de la marginalidad literaria permite revivir esa postura de aparente humildad que, como Jacques, simula inclinarse a los pies de su amo, pero solo para desamarrar más discretamente los cordones de sus botas y así preparar pérfidamente su inminente caída.

6 [Nota del autor]. Sobre esta interpretación de Jacques le fataliste, remito al lector a mi artículo "Jacques le fataliste: une ontologie de l'écriture pluraliste", (2008). Archives de philosophie, dossier Diderot Philosophe coordinado por Colas Duflo, 71(1), 77-93.

7 [Nota de los traductores]. Inglés en el original. 


\section{Maestría y espectáculo}

Al ocuparse del juego de su enunciación, la práctica literaria desmonta la maestría embrutecedora que contamina toda transmisión de contenido.

Jacques le fataliste et son maître no solo narra el viaje de los dos compañeros, sino que también escenifica al mismo tiempo las relaciones estrechadas entre Denis, el novelista, y su lector. Del mismo modo, Barthes habla de cenobitas, de matices, de Proust o del haiku al mismo tiempo que pone en escena constantamente la situación de habla que reúne a Roland el orador y su público. Los tres (Jacques, Denis y Roland) parecen entablar un juego (de roles, de pretensiones, de ilusiones, de mentiras, de exhibición) propio a la enunciación de un cierto tipo de discurso en cierto tipo de situación. El poder superior de las prácticas comunicativas de orden literario - en comparación con los modos de discurso no literarios- podría atribuirse a lo que saben realizar mediante su enunciación más de lo que pueden transmitir como contenido. Aunque muchos de nosotros pareciéramos todavía no ser conscientes de ello, un educador enseña más por lo que hace en clase (por la manera de comportarse con sus alumnos, sus conocimientos, y su institución) que por lo que dice (es decir, por el contenido informativo de su discurso). El modo de relacionarse mediante la cual pone en escena la transmisión de su saber cuenta tanto como la sustancia misma de su saber. Esto es lo que entendió tan bien Joseph Jacotot, cuya aventura pedagógica ha revindicado y revitalizado Jacques Rancière (1987) en El maestro ignorante: es el modo de relacionarse propio del discurso "explicativo" que embrutece al alumno. Si la educación comporta una dimensión emancipadora, no se debe tanto al contenido de lo que transmite sino a la construcción de roles que desarrolla a partir de los enunciados puestos en escena. Un maestro emancipador puede perfectamente enseñar lo que ignora, sin decir nada razonable sobre el contenido de lo que enseña, con tal de que su actitud consiga hacer comprender a los alumnos que ellos pueden encontrar en sí mismos los recursos (de atención) que necesitan para aprender. Las prácticas literarias — creativas e interpretativasparticiparían así de una competencia emancipadora propia, en la medida en que tienden a cultivar la conciencia más aguda de las implicaciones de la enunciación. Hablar o leer como literato implica fundamentalmente preguntarse cómo se escenifica la enunciación - lo que conduce a la vez a desmontar las arrogancias (un concepto barthesiano) propias de las posturas de la maestría y a inventar nuevas formas de comunicación más emancipadoras que embrutecedoras.

La competencia literaria ayuda a reconocer que los humanos actúan primero como actores y que toda maestría reposa sobre una lógica del espectáculo. 
Todos los relatos de cierto peso incluidos en el seno de Jacques le fataliste nos enseñan la misma lección antropológica: los humanos se condicionan mutuamente a través de máquinas de espectáculo con las que consiguen revestir sus acciones. Madame de la Pommeraie, el abad Hudson, el caballero de Saint-Ouin, y el mismo Jacques son tanto más eficaces cuanto más conciben sus acciones como gestos; uno es más agente (en vez de una víctima pasiva del destino) cuanto mejor sabes actuar. Esa lógica de espectacularización [spectacularisation] de lo real es llevada al extremo por otra novela de fines del siglo de las Luces: el Manuscrit trouvé à Saragosse de Jean Potocki (2007). En esta obra, es toda la realidad en la cual se encuentra el protagonista, Alphonse van Worden, durante su viaje por la Sierra Morena, la que resulta ser una enorme máquina de espectáculo. Y a través de ella, es toda la política mundial (los conflictos religiosos, los proyectos de una monarquía universal, los flujos de capital) que parece surgir de la puesta de escena y del storytelling. Lejos de ser ridiculizados, como el maestro de Jacques, los Gomelez que mueven los hilos de esta conspiración manipuladora representan un caso particularmente espantoso de la maestría: fanáticos islamistas, ellos tienen como proyecto convertir a todo el planeta a sus creencias intolerantes; beneficiarios de recursos ilimitados, logran montar un espectáculo perfectamente regulado que arrebata a sus víctimas lo que más estiman (su certeza, su semen). ${ }^{8}$ Aquí una vez más, la novela no pone en escena estos most unbecoming masters (desde el punto de vista de la Europa cristiana o racionalista) sin desinflar toda su pretensión a la maestría con un giro final. En el momento en que su plan diabólico parece triunfar de maravilla, todo su proyecto de conquista se desvanece, por no dejar de administrar de la forma más rentable una gran fortuna financiera. El unbecoming master del gran Ayatolla deja vislumbrar tras su máscara la cara más conocida, pero no menos inquietante del modesto MBA (Master of Business Administration)... Practicar la literatura es un ejercicio emancipador en la medida que nos enseña que toda maestría es el resultado de una lógica (ilusoria) del espectáculo, y no de un poder sustancial ante el cual nos veríamos obligados a inclinarnos por la fuerza de las cosas — cuando en realidad solo reinan captaciones (reversibles) de creencias y deseos. A través de novelas como Jacques le fataliste o el Manuscrit trouvé à Saragosse, adquiero la experiencia de que

8 [Nota de autor]. Sobre estas líneas de interpretación de la novela de Potocki, ver mis estudios "L'imprimerie des Lumières: filiations de philosophes dans le Manuscrit trowvé à Saragosse de Jean Potocki" (2007), en P. Hartmann y F. Lotterie (Eds.), Le Philosophe romanesque. L'image du philosophe dans le roman des Lumières (pp. 301-335). Presses universitaires de Strasbourg, "La mondialisation entre revenants et revenus : finances et liquidités chez Potocki" (2004), en M. Poirson (Ed.), Art et argent en France au temps des Premiers Modernes (XVIIe-XVIIIe siècles) (pp. 159-172). (Ser. Oxford University Studies in the Enlightenment, 2004:10), Liverpool University Press; y "Éditer un roman qui n’existe pas (mais qui réinvente les Lumières deux siècles après sa rédaction)" (2007). Revue Internationale des Livres et des Idées, 1, 4-6. 
la dominación es del orden de la puesta en escena (montaje) y que esta dominación solo reposa en las propiedades y las fragilidades de la puesta en escena.

\section{Desmontar la ambivalencia}

Hoy en día la competencia literaria consiste en saber movilizar las virtualidades de las formas discursivas para abrirse un camino entre las ambivalencias exacerbadas por nuestra época.

Varias razones nos pueden llevar a pensar que la ambivalencia llega a jugar un rol cada vez más central y cada vez más problemático en la medida de que nuestras formas de vida social se vuelven más complejas. La pregunta, "¿Es bueno o malo?" planteada por Diderot en su última obra de teatro, junto con la pregunta, "¿Estoy soñando o es realidad?" planteada por Alphonse van Worden durante sus primeros diez días en la Sierra Morena, resultan ser formulaciones muy torpes frente a las múltiples disyuntivas que son el pan cotidiano del mundo contemporáneo. Ha llegado a ser hasta inesperado, e incluso inquietante, imaginar una evolución de esta situación que uno podría decir con certeza ser totalmente deseable o totalmente rechazable. Los discursos tan promocionados sobre "la complejidad" tienen la contrapartida de hacernos oscilar sin cesar entre los pro y los contra ante cualquier situación o propuesta de reforma. Las prácticas literarias contribuyen sin duda a esta conciencia de la complejidad y de las aporías de la ambivalencia: una buena novela nos da una experiencia de un tal espesor de existencia que desmonta generalmente todo juicio simple y unívoco. No obstante, debido precisamente a este espesor, la experiencia literaria nos invita a ir más allá de la parálisis y del desconcierto que nos provoca la multiplicación de ambivalencias. En su segundo año de cursos en el Collège de France, Roland Barthes (31 y 37) definió lo Neutro como "aquello que desbarata [déjoue] el paradigma", y el mismo impulso lo lleva a ver en la literatura "un códice de matices" y "la maestra de los matices". El "proyecto ético" propuesto por la reflexión que desarrollaría hasta el final de su vida consistió en "intentar vivir según los matices que nos enseña la literatura”. En el mundo de la ambivalencia generalizada, las prácticas literarias nos enseñan a resistir a la vez a cualquier juicio simplista y juntamente cualquier trampa que nos tiende la estructura binaria de la alternativa (¿bueno o malo? ¿sueño o realidad?). A partir del momento en que el problema termina encerrado en tal estructura binaria - lo que Barthes denomina con el concepto de "paradigma" - padece de la ambivalencia como una especie de parálisis del pensamiento y de la sensibilidad.?

9 [Nota de autor]. Isabelle Stengers y Phillipe Pignarre (2004) han explorado este tema recientemente al plantear la manipulación de "alternativas infernales" (extender la jornada laboral u exponerse a la ex- 
La competencia literaria consiste entonces en saber contar más allá de dos, y en aprender a dar cuenta de los matices (potencialmente infinitos) que residen en nuestra realidad. Cuando, por la misma época, Gilles Deleuze llamaba a pensar "por el medio [par le milieu]", era también — entre otras cosas - para invitarnos a rehusar las alternativas simplistas, a fin de explorar y explotar las virtualidades que se atisban a través de los matices que constituyen la riqueza de toda situación concreta. Mientras que se trate de una sensibilidad con respecto a las formas, y que las formas concretas (de la vida y del arte) siempre superen las reducciones binarias a las que pueden ser sometidas, la competencia literaria consistirá, pues, en saber desmontar los paradigmas, y en inventar terceras (y enésimas) vías entre las ambivalencias que nos asedian por todas partes.

La competencia literaria requiere la capacidad (y ayuda posteriormente) a instalar grietas, intersticios, e biatos en los flujos de comunicación.

Cultivar las sutilezas que nos enseñan la práctica literaria implica poder resguardarse, en cierta medida, de las presiones que nos impulsan a reaccionar, transmitir, elegir y juzgar. Quienes comparten el proyecto ético literario esbozado por Barthes deben, por lo tanto, lograr como sugiere Gilles Deleuze (1985, p. 177), “poner a su disposición las vacuolas de soledad y de silencio desde los cuales se tendría finalmente algo que decir". Mientras que uno se limite a elegir entre las alternativas planteadas por otros (como es el caso en las encuestas), mientras uno se limite a reaccionar ante la situación tal y como se presenta, y mientras uno se limite a responder a las preguntas tal cual son planteadas, uno caerá en el juego de la arrogancia de los maestros del debate público. Desmontar la maestría implica, antes que nada, protegerse de los flujos de comunicación que nos llegan del mundo exterior. De la misma forma que Virginia Woolf exigía el espacio de un "cuarto propio" para estar en condiciones de escribir su obra literaria, nosotros debemos comenzar por (y exigir poder) cortar nuestro teléfono y correo electrónico, y no responder a las demandas de los informes administrativos, las evaluaciones, las cartas de recomendación, las solicitudes, y los eventos de extensión, si pretendemos algún día "tener algo que decir" que se escape de aquellas alternativas que no hacen más que repetir lo mismo. Es en el marco de tales hiatos que puede desarrollarse una competencia literaria que utiliza el intersticio generado - al interior de los flujos de comunicación - entre la acción sufrida y la reacción producida, entre la pregunta y la respuesta, para producir una brecha significativa al interior de los modos

portación de los trabajos al extranjero) como un tropo esencial dentro de la magia retórica del discurso capitalista. 
discursivos. La producción de esta brecha significativa es el principal objetivo de la performance literaria.

\section{Aprender a no afirmar ni comprender}

La performance literaria nos brinda la protección de una enunciación indirecta, derivada, y resguardada tras la palabra ajena al interior de un proceso que surge a partir de la transducción.

Mientras que el filósofo, el científico o el político deben arriesgarse a emitir afirmaciones de las que son plenamente responsables, el literato enuncia un discurso siempre enmascarado. Ya sea el escritor que habla siempre bajo la apariencia de un narrador o de un enunciador paratópico, o el crítico que no aspira sino a comentar un discurso ajeno, la enunciación literaria ofrece la inestimable comodidad de poder hablar disimuladamente. Si existe una maestría constitutiva de la práctica literaria, es justamente aquella que me permite expresar lo que yo creo constituir una diferencia significativa, a través de la puesta en escena de lo que otro ha dicho antes que yo. En este caso, la maestría consiste también en desmontar la posición de maestría que pesa sobre todo acto de habla: cualquier enunciado puede en efecto ser enmarcado por la precisión (inútil): “el hablante afirma que...”. El dispositivo propio a los estudios literarios consiste justamente en neutralizar esta dimensión de afirmación personalizada que parece ser constitutiva del habla humano. La competencia que debe aprender los estudiantes, mediante toda una serie de técnicas y ritos transmitidos en las facultades de Letras, es precisamente la de saber hablar disimuladamente para hacer pasar sus afirmaciones como las de un otro. El juego de la competencia literaria consiste, entonces, en desmontar la pretensión de maestría inherente al discurso individualizado, gracias al dominio de los procesos interpretativos implicados en la transducción.

La práctica de la explicación de textos es la que mejor ejemplifica la competencia literaria, siempre y cuando concentre el ejercicio de la maestría en aquello que se escapa de la maestría.

Al contrario de lo que creen muchos estudiantes traumatizados por la ortopedia de los exámenes, la explicación de texto no consiste en mostrar que uno "comprendió bien” el texto seleccionado. Toda su dinámica se basa, por el contrario, en la capacidad de saber identificar algo que se nos escapa, el punto en el que el texto "se fuga", las grietas, los intersticios, las disyuntivas o los excesos por los cuales el texto resiste al esfuerzo de ser "bien entendido". Como cualquier "investigador", el literato solo se digna prestar atención a lo que no comprende. Ahora bien, nada 
es más difícil. Y la cumbre de la competencia literaria — por lo que es más una cuestión de sensibilidad que de un saber propiamente tal- consiste en aprender a no comprender los textos que uno lee, es decir a no caer en los significados (las alternativas o los paradigmas) a través de los cuales uno es llevado a reaccionar de forma espontánea e inmediata (como resultado de la adquisición de una competencia). La "explicación" de texto es muy mal nombrada, ya que nos sugiere el "maestro explicador" denunciado por Jacotot y Rancière. Si bien se trata de "desplegar" ("ex-plicare") los nudos que dan densidad al texto, no sería cuestión de explicar lo que el texto mismo dice ("ipero el lector medio sería muy idiota para poder entenderlo todo por su cuenta!" exclamarían los maestros explicadores): este hecho asemejaría la "explicación” de texto a los ejercicios pedagógicos que Jacotot y Ranciére califican de "embrutecedores". Al contrario, una buena explicación de texto debe necesariamente comenzar por desmontar el tipo de maestría que presume el "maestro explicador": debe comenzar por exponer su propia incapacidad para dar cuenta del texto dentro del marco de los paradigmas que dispone. Saber reconocer o introducir intersticios y disyuntivas dentro de un texto, ser sensible a los matices que desdibujan los paradigmas que instintivamente imponemos sobre él, mobilizar aquellos matices para extraer nuevas sutilezas de esos paradigmas, desconfiar de las tachaduras producidas por el supuesto refinamiento que uno aporta a los paradigmas, todo esto define bien la competencia literaria como el juego de una maestría cuyo primer y último objetivo es desmontar la maestría.

\section{La literatura como gusto y contaminación}

¿Qué se aprende al estudiar la literatura? ¿Cómo rebatir los ataques ideológicos y presupuestarios en contra de los estudios literarios? ¿Cómo superar la indiferencia que los amenaza? Para responder a estas tres preguntas a la vez, concluiré con retomar el concepto de "transducción", según lo define Simondon, como una operación "mediante la cual una actividad se propaga paso a paso". Las facultades de Letras enseñan una especie de contaminación "paso a paso", y debemos contar con los efectos de esta contaminación para promover la continuidad y desarrollo de los estudios literarios.

Como Barthes había intuido muy bien durante los años 1970, los estudios literarios hoy por hoy provienen de prácticas "minoritarias", e incluso oposicionales. No hay que lamentar este hecho: el uso "mayoritario" de la literatura como una forma de cultura dominante generó efectos de embrutecimiento y opresión que nadie debe añorar. Ahora podríamos tomar el partido de aquellos que han sido excluidos por los efectos de embrutecimiento y opresión inherente a esta concepción 
anticuada de los estudios literarios, y procurar atraerlos a su ejercicio. Podemos aprovechar esa moda perenne de las artes marciales para presentar los estudios literarios como un aprendizaje — lento, paciente, y riguroso- de técnicas de combate intelectual, de un arte de la guerra de significaciones y de valores. Al contrario de las jerimiadas nostálgicas y reaccionarias que circulan tanto entre nosotros, el "proyecto de autonomía" que Castoriadis oponía al projecto de "maestría racional" emprendido por "el capitalismo" aun no ha perdido la guerra. El error, una vez más, consiste en oponerlos de forma binaria, pues sus ambivalencias incitan a enfocarnos en los matices de lo que se genera en el seno (au milieu) de su oposición.

Las prácticas literarias convocarán a numerosos combatientes en cuanto logremos demonstrar, de poco a poco, en qué medida son íntimamente conducentes al proyecto de autonomía que opera en el fondo de nuestras sociedades, y en qué medida son igualmente necesarias para la expansión del mismo proyecto de maestría racional (que cada vez menos se puede confundir con el desarrollo errático del capitalismo). Al desarrollar un tipo de maestría propia de la crítica, y al superar las maestrías que reclaman los dirigentes, expertos, sabios y profesores de toda pinta, los estudios literarios asumen una postura que, como yo he intentado sugerir aquí, era la que tenía la literatura desde los origines de la modernidad. El hecho de que esa postura indirectamente oposicional, hecha de humildad, de servitud rebelde, y de juego espectacular se encuentre hoy día bajo el alero de instituciones universitarias que son financiadas por el Estado, por los flujos de capital o por la lógica de la inversión en capital humano — cualquiera que sea su fuente, se verá mal a priori, dado que se trata de una actividad oposicional - esto obviamente constituye una de las mayores contradicciones y ambivalencias de nuestra situación actual.

Es precisamente en el hecho de esta fragilidad institucional que la salvación de nuestras prácticas se debe buscar por el lado de la contaminación progresiva. Si la experiencia literaria constituye una "forma de vida" (como ha defendido Barthes), debe contar, antes que nada, con el dinamismo de su propia vida para afirmarse en un mundo que no le es fatalmente hostil. Más allá de las cuestiones de competencias, de disciplinas y de maestría (que son no obstante precondiciones imprescindibles de la práctica literaria), a mi me gustaría concluir vinculando esta práctica a una cuestión de gusto y de deseos. En este punto me uno a lo que Stanley Fish (1985, p. 111) dio como la última justificación de los estudios literarios: "I do it because I like the way I feel when I am doing it'.10.

¿No es acaso esta necesidad — propiamente desesperada - del tipo de experiencia que nos brindan los estudios literarios lo que nos reclaman cotidianamente las

10 Inglés en el original: "Lo hago porque me gusta como me hace sentir cuando lo hago". 
montañas de depresiones, psicotrópicos o de asesinos desquiciados (virtuales) que pueblan nuestra sociedad? Es dudoso que la práctica literaria de explicación de textos "salve el mundo". Ni siquiera es seguro que las universidades sigan patrocinando los estudios literarios por mucho tiempo más. Sin embargo, lo que sí podemos hacer como resistencia desde ahora es mostrar — más modestamente, pero la modestia les queda bien - cómo nos ayudan a vivir. El juego no está perdido mientras que, en la época de las sociedades de control, la difusión de los deseos y gustos siga siendo el modo primordial de esculpir nuestras formas de vida colectiva. 


\section{Obras citadas:}

Barthes, R. Le Nuetre. Cours au Collège de France 1977-1978. Seuil, 2002.

Castoriadis, C. "L'époque du conformisme généralisé". Le Monde morcelé. Les carrefours du labyrinthe III. Seuil, 1990: 11-24.

Deleuze, G. Les intercesseurs, en Pourparlers. Minuit, 1990: 165-84.

Fish, S. Professional Correctness. Literary Studies and Political. Clarendon Press, 1985.

Potocki, J. Manuscrit trouvé à Saragosse (F. Rosset et D. Triaire, Eds.), 2007.

Rancière, J. Le maître ignorant. Cinq leçons sur l'émancipation intellectuelle. Fayard, 1987.

Simondon, G. L'individuation psychique et collective. Aubier, 1989.

Stengers, I. y Pignarre, P. La sorcellerie capitalista. Practiques de désenvoûtement. La Découverte, 2004. 